\title{
MUJERES Y JUGLARÍA EN LA EDAD MEDIA HISPÁNICA: ALGUNOS ASPECTOS
}

\author{
Donatella Siviero \\ Università di Messina \\ dsiviero@unime.it
}

\begin{abstract}
Resum
A partir del análisis del personaje de Tarsiana del Libro de Apolonio (primera mitad del siglo XIII), se analizan las figuras de las cantaderas y danzaderas, es decir, las juglaresas que acompañaban a los juglares y trabajaban a su lado, compartían su vida errante y obtenían una remuneración gracias a sus actuaciones públicas. Las juglaresas, también llamadas soldaderas porque ganaban la 'soldada' o sueldo diario, tenían mala reputación, hasta el punto de ser consideradas prostitutas, aunque muchas de ellas no ejerciesen como tales e incluso tuvieran cierto nivel cultural. El propósito de este artículo es subrayar una vez más que la realidad artística de la juglaría femenina debió de ser bastante más compleja de cuanto dejan traslucir las reconstrucciones hechas durante siglos desde una perspectiva predominantemente masculina.
\end{abstract}

\section{Paraules clau}

Libro de Apolonio, juglaría femenina.

\begin{abstract}
Starting from the analysis of the character of Tarsiana in the Libro de Apolonio (first half of the I3th century), this article discusses the figures of the cantaderas and danzaderas, i.e., the juglaresas, women performers who accompanied the jongleurs and worked at their side, shared their wandering life and received compensation for their own public performances. The juglaresas, called also soldaderas because they earned a daily wage, had a bad reputation to the point of being considered prostitutes, although most of them did not practice prostitution and could even be quite cultured. The purpose of this article is to emphasize once more that the artistic reality of female minstrelsy was rather more complex than transpires from the reconstructions made over the centuries from a predominantly male perspective.
\end{abstract}

\section{Keywords}

Libro de Apolonio, feminine minstrels. 
El Libro de Apolonio, el poema anónimo castellano en cuaderna vía de la primera mitad del siglo xiII, nos ha dejado un testimonio muy importante acerca de la figura de la juglaresa y de su oficio en la Edad Media. Procedente de una redacción latina de la Historia Apollonii regis Tyri, ${ }^{\mathrm{I}}$ que tuvo gran difusión en la Edad Media, ${ }^{2}$ el Apolonio cuenta las peripecias vitales de Apolonio, su mujer Luciana y su hija Tarsiana en un complicado encadenamiento de encuentros, separaciones, naufragios, raptos e inesperadas reuniones, según el modelo de la ficción bizantina. Pese a derivar de una fuente cierta, el Apolonio tiene un marcado carácter original, pues su anónimo autor incluyó en él varias aportaciones personales, así como importantes detalles propios de la realidad castellana del siglo xir.. ${ }^{3}$ Tal es el caso de las estrofas 426 y 427 , donde se encuentra la escena de juglaría femenina a la que acabo de referirme:

Luego el otro día, de buena madurgada, levantóse la dueńa ricamient'adobada; priso una viola, buena e bien temprada, e salió al mercado violar por soldada.

Comenzó unos viesos e unos sones tales, que trayén grant dulçor e eran naturales, finchíense de homnes apriesa los portales, non cabién en las plaças, subién a los poyales. ${ }^{4}$

La "dueña" que "priso una viola" y "salió al mercado violar por soldada" es la hija de Apolonio, Tarsiana. Estamos en la parte del libro donde se cuenta que la joven, separada al nacer de sus padres biológicos y criada por padres adoptivos, ha sido raptada y luego vendida en subasta al dueño de un burdel. Este "homne

I En el pasado algunos estudiosos sugirieron un origen francoprovenzal del poema castellano, pero la dependencia directa de la fuente latina está muy bien documentada. Sobre la cuestión, véase C. Monedero, "Introducción" a Libro de Apolonio, ed. C. Monedero, Madrid, 1987, pp. I6-I8.

2 I. Lozano-Renieblas, en Novelas de aventuras medievales. Género y traducción en la Edad Media hispánica, Kassel, 2003, p. 37-74, traza una panorámica acerca de los problemas de origen, lengua y transmisión de la Historia Apollonii regis Tyri y subraya que ésta "contó con una excepcional acogida en la Edad Media, a juzgar por el centenar largo de manuscritos latinos conservados” (p. 38).

3 La fuente principal es la Historia Apollonii Regis Tyri, probablemente de la primera mitad del siglo III d. C. Sobre la originalidad del Libro de Apolonio, véase M. Alvar, Libro de Apolonio. Estudios, ediciones, concordancias, Madrid, 3 vols., I976, vol. I, pp. II3-I82; M. Alvar, "La originalidad española del Libro de Apolonio", Actas de las III Jornadas de Estudios Berceanos, ed. C. García Turza y otros, 198I, pp. 19-32; C. Alvar y M. Alvar, "Apollonius-Apollonie-Apolonio: la originalidad en la literatura medieval”, Comentario de textos, IV, Madrid, I983, pp. I25-I47.

4 Todas las citas del Libro de Apolonio son de la edición de M. Alvar, Madrid, 1976; indico los versos entre paréntesis. 
malo, señor de soldaderas" (396a) pone en venta la virtud de Tarsiana a un alto precio: "Qui quisiere Tarsiana primero cońoscer, / una libra de oro habrá a poner, / los otros sendas onzas habr'an a ofrecer" (4orb-d). Pero Tarsiana logra persuadir al príncipe Antinágora, quien ha comprado su virginidad, y a los otros sucesivos clientes para que no consumen el acto carnal por el cual han pagado contándoles sus desventuras (vv. 406-419); y luego convence al proxeneta de que conseguirá más dinero con ella si, en vez de explotarla como prostituta, la deja ejercer como juglaresa: "Señor, si lo hobiese yo de ti condonado, / otro mester sabía que es más sin pecado, / que es más ganancioso e es más hondrado" (422b-d).

Lo que nos interesa subrayar en primer lugar es que la escena dibujada en las estrofas 426 y 427 constituye una de las pocas descripciones literarias medievales de cómo podía ser la actuación de una juglaresa en una plaza en aquella época. En este sentido, es muy importante señalar que, en la fuente latina, la escena en la cual Tarsiana canta es algo diferente, pues allí no se hace ninguna referencia al modo en que actúa la joven ni al lugar donde lo hace..$^{5}$ Así pues, el autor anónimo del Libro castellano no se conforma con el original, sino que adapta la escena a la realidad de su tiempo, la amplía con la descripción de la actuación y nos ofrece, por así decirlo, una instantánea, el retrato de una mujer ejerciendo de juglaresa. En opinión de Pedro José Pidal, aquí el poeta "seguramente no hace más que describir lo que veía todos los días"; ${ }^{6}$ y, según Manuel Alvar "Tenemos ante los ojos una escena de juglaría: desde la mujer que va a actuar hasta los desocupados que se empinan en los trancos de las puertas o se suben a los poyos y, por supuesto, los lamentos del canto". ${ }^{7}$

La originalidad de la escena radica en el hecho de que la protagonista de la actuación pública es una mujer, ya que las descripciones del mundo de la juglaría que se encuentran en otras obras literarias medievales normalmente hacen referencia a juglares hombres. En el poema narrativo Flamenca, por ejemplo, obra en provenzal contemporánea del Libro de Apolonio, el autor anónimo presenta una actuación tras un banquete de una muchedumbre de juglares, y todos ellos son hombres. ${ }^{8}$ Volviendo al área castellana, lo mismo ocurre en la descripción de una

5 Ésta es la escena en la Historia Apollonii Regis Tyri: "Puella respondit: 'Habeo auxilium studiorum liberalium, perfecte erudita sum; similiter et lyrae pulsum modulanter inlido. Iube crastina die in frequenti loco poni scamna, et facundia sermonis mei spectaculum praebeo; deinde plectro modulabor et hac arte ampliabo pecunias cotidie.' Quod cum fecisset vilicus, tanta populi adclamatio tantusque amor civitatis circa eam excrebuit, ut et viri et feminae cotidie ei multa conferrent." (Historia Apollonii Regis Tyri, eds. D. Konstan y M. Roberts, Bryn Mawr, PA, 1988, p. 2I).

6 P. J. Pidal "De la poesía castellana en los siglos XIv y Xv", en El Cancionero de Juan Alfonso de Baena, 2 vols., ed. F. Michel, Leipzig, I860, vol. II, pp. I-CXIX, p. XVI.

7 M. Alvar, Libro de Apolonio. Estudios, p. I6I.

8 Se trata de una larga descripción (versos 594-733) de una fiesta donde los juglares tocan dife- 
escena de juglaría del Libro del caballero Zifar, obra de comienzos del siglo xiv, donde todas las referencias son también a juglares:

E desque ouieron comido, leuantaron las mesas muy toste, e ally fueron llegados muy grant gente de joglares; e los vnos tanien estrumentos, e los otros saltauan, e los otros tunbauan, e los otros subian por los rayos del sol a las feniestras de los palaçios que eran mucho altos, e desçendian por ellos bien asy como sy desçendiesen por cuerdas, e non se fazian mal ninguno. "Señora", dixo el cauallero, "que es esto por que aquellos omes suben tan ligeramente por el rayo del sol e desçienden?". "Çertas", dixo ella, "ellos saben sus encantamentos para fazer estas cosas atales. E non seades quexoso para querer saber todas las cosas en vna ora, mas ved e callat, e asy podredes las cosas mejor saber e aprender; e las cosas que fueron fechas en muy grant tienpo e con grant estudio, non se pueden aprender en vn dia”. ${ }^{9}$

En cambio, hallamos una breve mención a unas "juiglesesses” en una escena cortesana del Roman de la rose de Guillaume de Lorris, obra en francés de la primera mitad del siglo xiIr, y una pequeńa referencia a la actuación de una juglaresa en otra obra provenzal, el cantar de gesta Daurel e Beton (II8O-I2IO). Los versos 752-770 del Roman de la rose describen una carola, una danza en un vergel. Con todo, esta escena no es tan detallada como la de Tarsiana y, además, hace referencia a una actuación en un espacio privado, en una fiesta, no a una actuación pública. Estos son los versos a los que me refiero:

\author{
Asez avoit tableresses \\ Iqui encor et juiglesesses \\ Qui mout savoient bien joer, \\ Qui ne finoient de ruier \\ Le timbre en haut, sel recuilloient \\ Sor .i. doi, c'onques n'i failloient. \\ .Ij. damoiseles mout mignotes \\ Qui estoient en pure cotes \\ Et trecies a une trece \\ Faissoit deduiz par grant noblesce \\ Enmi la querole baller, \\ Mes de ce ne set on parler \\ Com el balloient cointement. \\ L'une venoit tot belement
}

rentes instrumentos, recitan obras literarias y hacen juegos acrobáticos. El autor anónimo es prolijo a la hora de enumerar instrumentos musicales y obras literarias, pero no hace referencia alguna a la posible presencia de mujeres entre el grupo de juglares. Cfr. Flamenca. Romanzo occitano del XIII secolo, ed. R. Manetti, Modena, 2008.

9 Libro del caballero Zifar, ed. C. GonZÁLEZ, Madrid, I983, p. 243. 
Contre l'autre, et quant estoient

Pres a pres, s'antregitoient

Les bouches, qu'il vos fust avis

Qu'il s'entrebesent el vis.

Bien se savoient debrisier. ${ }^{\text {IO }}$

En Daurel e Beton si muchas son las referencias al arte del juglar protagonista, Daurel, solamente en una ocasión, en los versos 203-205, se cita a su mujer actuando con él: "Abtant vec vos la molher del joglar, / E Daurel veiuela, ela presa a tombar, / Denan la dona gen si van deportar"."

El Apolonio, pues, como decía ofrece el inusual y bastante detallado retrato literario de una juglaresa actuando con su traje de escena ("ricamient'adobada") y su instrumento (la "viola buena e bien temprada") en una plaza pública. ${ }^{12}$ El lector que llega a este punto del Libro sabe que Tarsiana puede ejercer este oficio porque desde su niñez había estudiado música y había aprendido a tocar y cantar. Tal como se cuenta anteriormente en el libro, la joven había recibido una excelente educación: "Cuando fue de siet’años, diéronla al escuela; / apriso bien gramátiga y bien tocar vihuela" (350 b-c); más tarde, "Cuando a Xv años fue la dueña venida, / sabía todas las artes, era maestra complida" ( $352 \mathrm{a}-\mathrm{b}$ ). Además, siempre fue muy diligente, ya que "Non querié nengún día su estudio perder, / ca habié voluntat de algo aprender" (353 a-b). Es más: Tarsiana no solamente conoce "unos viesos y unos sones tales, / que trayén grant dulzor y eran naturales", sino que es capaz de componer las canciones que ejecuta, pues, como se dice en la estrofa 428 , canta para el público el romance de su vida:

Cuando con su viola hobo bien solazado, a sabor de los pueblos hobo asaz cantado, tornóles a rezar un romanz bien rimado, de la su razón misma, por ó habiá pasado.

La actuación pública de Tarsiana empieza con unas canciones genéricas para luego convertirse en el relato cantado de su historia autobiográfica, una historia que ella transforma en argumento para componer un romance, esto es, un cuento

io Guillame de Lorris y Jean de Meun, Le roman de la rose, ed. A. Strubel Paris, 1992.

in Daurel e Beton, ed. C. Lee, Parma, i99i.

I2 J. C. Musgrave señala que "Although the poet distinguishes between Tarsiana and the ordinary juglaresa, the description of her performance in the market place is nevertheless of interest in relation to poetic generes. [...] First she sang unspecified lyrics, then recited the story of her life. [...] Romance was used vaguely in the sense of a vernacular narrative poeme." ("Tarsiana and Juglaría in the Libro de Apolonio", en Medieval Hispanic Studies presented to Rita Hamilton, ed. A. D. Deyermond, London, I976, pp. I29-I38, p. I36.) 
novelado. ${ }^{13}$ Sabemos, como acabo de decir, que la joven es "maestra complida" (352b) y sabemos que es de origen real, lo cual significa que ejerce el mester de juglaría con conocimientos propios del mester de clerecía, un "mester sin pecado", según las palabras que el poeta le pone en boca, jugando así con el doble sentido que tal afirmación puede cobrar en el contexto: su oficio de juglaresa, un mester de gran maestría y sabiduría, impide a Tarsiana caer en el pecado de la prostitución, al que se ve condenada en contra de su voluntad. ${ }^{14}$ Conviene remarcar que, en el Libro, el rol de juglaresa se opone decididamente al de prostituta, algo que no era habitual en aquella época ${ }^{15}$ y que confirma la importantancia testimonial de dichos versos.

Como es bien sabido, en la segunda estrofa del Libro de Alexandre, obra contemporánea de nuestro Apolonio, el igualmente anónimo autor afirmaba que su mester fermoso no era de juglaría, sino de clerecía y sin pecado y preveía "fablar curso rimado por la cuaderna vía, / a sýlabas contadas, que es gran maestría" (2c-d). ${ }^{16}$ En el mismo Libro de Alexandre, por boca del príncipe Alexandre (vv. 40-45) se explica que la clerecía se compone en primer lugar de gramática, lógica y retórica, es decir, el trivium, y se completa con el conocimento de dos artes del quadrivium, música y astronomía. La clerecía, pues, no es "just erudition, but

I3 "The description of her performance in the market place is nevertheless of interest in relation to poetic genres. [...] First she sang unspecified lyrics, then recited the story of her life. [...] Romance was used vaguely in the sense of a vernacular narrative poem in the twelfth and thirteenth centuries." (ibidem). Véase también G. Hilty, "La figura del juglar en la Castilla del siglo xiı", Versants, XXVIII, I995, pp. 153-I73, p. I72; para otro ejemplos en la literatura rómanica medieval de pseudoautobiografismo de componimientos atribuidos a personajes de ficción, cfr. M. G. Capusso, "Performances giullaresche, ricapitolazioni e riconoscimenti”, en Ogni onda si rinnova. Studi di ispanistica offerti a Giovanni Caravaggi, 3 vols., eds. A. Baldissera, G. Mazzocchi, P. Pintacuda, Pavia, 20II, vol. I, pp. 5I-76.

I4 "Here, perhaps, the poet is playing upon the belief that the juglaresa is little better than a prostitute. [...] A juglaresa would have been expected to sin sexually; that Tarsiana does not seems to indicate that, just as she was not a real prostitute, neither is she a real juglaresa. The dissociation is made implicitly by Tarsiana, when, during her performance, she tells the story of her life (428-9a). It seems reasonable to conclude that the distinction which she draws between herself and the ordinary juglaresa (490-I) is foreshadowed in the earlier passage (422-33)" (J. C. Musgrave, "Tarsiana and Juglaría”, pp. I33-I34).

is Cfr. P. Caraffi, quien señala que "Il fatto di conoscere la musica, di per sé segno di cultura 'alta', perché compresa tra gli insegnamenti dello studium universitario, non significa che fosse lecito suonare per un pubblico, e soprattutto a pagamento" ("Tarsiana, nobile giullaressa”, en Figure femminili del sapere (XII-XV secolo), Roma, 2003, pp. 9I-I22, p. IO7).

I6 Sabido es que no debemos interpretar estos versos como una declaración hecha con el fin de contraponer ambos mesteres, pues ello sería incierto. Tal como dice A. Deyermond: "We sholud perhaps consider the possibility that, were it not for the words of one thirteenth-century poet, nobody would have thought of dividing early narrative poetry into two watertight compartments" ("Mester es sen pecado", Romanische Forschungen, LXXVII, I965, pp. III-II6, p. II2). 
something closely identified with the studium of school or university." ${ }^{{ }_{17}}$ Quién ejercía dicho mester tenía un elevado nivel de cultura, nivel que, lo repito, posee la misma Tarsiana. De hecho, la joven se salva a través del camino de su sabiduría, al transformarse en juglaresa, una juglaresa sin pecado, honesta y al mismo tiempo conocedora de la clerecía.

No se trata, pues, de una juglaresa cualquiera; el autor lo vuelve a subrayar en una escena sucesiva, en el momento de la historia en que Tarsiana y Apolonio se encuentran por primera vez después del abandono acontecido quince años atrás. Ambos aún desconocen sus respectivas identidades y su parentesco, y Tarsiana le explica a ese señor, que para ella todavía es un desconocido, que no pertenece a la condición de las juglaresas de bajo nivel:

Por mí, solaz non tengas, que eres ahontado;

si bien me conoscieses, tener t'hies por pagado, ca non só juglaresa de las de buen mercado, nin lo he por natura, mas fágolo sin grado. (490)

El verso 490a, con la puntuación que propone la edición de M. Alvar, plantea algunos problemas de interpretación: con las comas así colocadas, el verso querría decir "no tengas solaz de mí porque serías deshonrado", lo cual carece de sentido, ya que Tarsiana ha sido convocada allí precisamente para que distraiga al afligido rey. ${ }^{18}$ Por lo tanto, creo que el verso se tendría que leer sin comas, como proponen las otras ediciones del Libro de Apolonio, "Por mi solaz non tengas que eres aontado", ${ }^{\text {,9 }}$ porque lo que hace Tarsiana aquí es tranquilizar a Apolonio explicándole que tiene delante a una juglaresa especial, cuya condición y naturaleza son más altas de cuanto se pueda inferir de su aspecto y sus acciones. Además, la joven recalca ante su interlocutor que no es juglaresa "por natura", es decir, por su disposición natural, y que ejerce dicho oficio "sin grado", sin complacencia. ${ }^{20}$

I7 R. S. Willis, "Mester de clerecía: a definition of the Libro de Alexandre", Romance Philology, x (1956-57), pp. 2I2-224, p. 2I4. Cfr. también F. Rico, Primera cuarantena y Tratado general de literatura, Barcelona, 1982, pp. 49-51.

I8 Para la cuestión de la interpretación de este verso, véase J. L. Girón AlConchel, Comentario de textos de clerecía: "Alexandre" y "Apolonio", Madrid, 2002, pp. 63-64.

I9 Leen el verso sin las comas las ediciones del Libro de Apolonio de P. J. Pidal (Madrid, I864), Ch. Carroll Marden (Baltimore, 1917), G. B. De Cesare (Milano, I974), C. Monedero (Madrid, I987), D. Corbella Díaz (Madrid, I992).

20J. GARCía ÚNiCA señala que en la estrofa "Verso a verso la lógica feudal se desarrolla de manera impecable: a) Por mi solaz non tengas que eres aontado: Apolonio no debe sentir vergüenza por estar delante de una juglaresa, en primer lugar porque es un rey lazrado que ha pasado mil penalidades y, en segundo, porque precisamente por eso a su condición corresponde también procurar alegría y descanso para su corazón; b) sy bien me conocieses, tenerte yes pagado: Apolonio no lo sabe aún pero 
A través de las palabras de Tarsiana intuimos que en aquel entonces existían como mínimo dos tipologías de juglaresas: la primera, a la que ella — según afirma con un deje de orgullo - pertenece, aunque "sin grado", es la tipología de las juglaresas que ejercían un "mester sin pecado"; la segunda, la de las juglaresas de "buen mercado".

Llegados a este punto, creo necesario abrir un pequeño paréntesis para recordar que en la Edad Media el oficio de juglares y juglaresas fue muy variado y que existieron muchísimas clases de juglares. El término 'juglar' era muy ambiguo y muy poco claro, ya que se usaba para designar tanto al intérprete, como al recreador y adaptador de los textos o al simple instrumentalista, y tanto a los profesionales como a los que se improvisaban artistas. ${ }^{21}$ La confusión era tal que, en I274, al trovador Guiraut Riquier, el cual vivió en la corte de Alfonso x el Sabio entre 1270 y I280, le pareció necesario escribir una Suplicatio al rey para pedirle que pusiera orden en el confuso mundo de la terminología juglaresca ${ }^{22} \mathrm{y}$, sobre

está ante una maestra complida a la que, además, se le suma la beltad conpanyera (c. 352c, 192) que habrán de confirmarse en todo momento porque, como hija (oculta, pero hija) del rey de Tiro, Tarsiana no podrá evitar mostrar los signos sustanciales del alto linaje del que proviene, es decir, no podrá, ni aún lejos todavía de ser restituida a su lugar natural, ocultar poseer la maestría ni la beldad que, en el lógico proceso -tan propio de las narraciones caballerescas- de desconocimiento/ revelación/restitución de su linaje, se van a ir remachando a cada paso; c) qua non só juglaresa de las de buen mercado: obviamente, a diferencia de estas mismas estructuras caballerescas en su variante masculina, Tarsiana no puede 'revelarse' como caballero, pero puede dominar las artes de la música con maestría, es decir, sin pecado y lejos del buen mercado, del ejercicio de la ganancia mercantil que buscan los juglares al uso, porque Tarsiana, insistamos, no puede sino señalar sin saberlo su alto linaje; y d) nin lo é por natura, mas fágolo sin grado: ¿cómo iba a ser, en el fondo, la hija del mejor de los reyes una mera juglaresa? Eso es algo que, como muy bien indica este certero alejandrino, no puede darse por natura, y en consecuencia Tarsiana no podrá evitar ser una maestra conplida que sin grado deba dedicarse a un oficio alejado de su condición" ("De juglaría y clerecía: el falso problema de lo culto y lo popular en la invención de los dos mesteres", Espéculo. Revista de estudios literarios, 2009, <http://www.ucm.es/info/especulo/numero42/dejuglar.html>).

2I En ocasiones, el cantor se acompañaba tocando él mismo un instrumento musical; también podía ser autor de los textos que recitaba y cantaba.

22 Guiraut Riquier se lamenta de que llamen juglares indistintamente a profesionales y aficionados y de que con el tiempo haya ido creciendo el número de los que actúan indignamente: "c'una gens s'es moguda / ses sen e ses saber / de far, de dir plazer / e senes conoisensa” (vv. 620-62I). En la respuesta de $\mathbf{2} 275$, la Declaratio, compuesta por el mismo trovador, si bien éste la atribuyó al rey Alfonso, quien muy probablemente le dio algunas sugerencias acerca del tema, se explica que en castellano llaman joglars a los que tocan instrumentos, remendadores a los que hacen imitaciones, segriers a los que componen, es decir, a los trovadores, mientras que a los incapaces e indignos los llaman cazuros, y se sugiere también una terminología para el provenzal. En esta última lengua, el término joglar se debe utilizar para los buenos ejecutores y para quienes saben actuar bien en público. Sobre la cuestión, cfr. V. Bertolucci Pizzorusso, "La Supplica di Guiraut Riquier e la risposta di Alfonso x di Castiglia”, Studi mediolatini e volgari, I4, 1966, pp. 9-I37 y C. Di Girolamo, I trovatori, Torino, 1989, pp. 228-232. 
todo, para evitar que llamasen juglares a quienes no merecían tal denominación, es decir, a quienes podríamos clasificar como "de buen mercado".

Entre estos artistas, profesionales o aficionados, no eran infrecuentes las presencias femeninas; sabemos, y la iconografía de algunos manuscritos medievales así lo confirma, que hubo juglaresas que actuaban a lado de los juglares. Y sabemos que las juglaresas también tenían diferentes especialidades, aunque las principales eran ser danzadera (bailarina) y cantadera (cantante). Al igual que los juglares, ellas se ganaban la vida con sus actuaciones. Numerosas miniaturas representan a mujeres artistas danzando, o acompañándose de instrumentos como castańuelas o panderos; en cambio, los juglares suelen aparecer tocando instrumentos de cuerda o de aire. Así, por ejemplo, en doce de las dieciséis miniaturas del Cancioneiro de Ajuda (I280-I300), al lado del juglar que toca vemos a una mujer bailando y/o tocando un instrumento de percusión. ${ }^{23}$ Lo cierto es que, en el ámbito de la lírica gallego-portuguesa, las cantadeiras tuvieron un papel muy importante en la interpretación de las cantigas de amigo, cuyas estrofas paralelísticas las cantaban dos o más intérpretes alternándose los versos. Es evidente que en las actuaciones juglarescas había a menudo presencias femeninas, pues, como recuerda Francisco Rico, el juglar:

rara vez viajaba sin una hembra al lado, y no, claro está, de convidada. Amén de otras faenas, a la juglaresa le tocaba regularmente añadir vistosidad a la función bailando al ritmo del pandero y por ello mismo, sin necesidad de más (y muchas veces lo había), convirtiendo su cuerpo en espectáculo. A pocas dotes que tuviera para el cometido, la danzadera se doblaba asimismo en cantadera, y en su caso intervenía en la (re)presentación de los episodios dialogados. (Es bien significativo al respecto que la popularísima modalidad poética del debate enfrente principalmente a un personaje masculino y otro femenino: el alma y el cuerpo, el agua y el vino $[\ldots])^{24}$

Junto a los términos cantadera y danzadera, que, claro está, guardaban relación con el papel de las mujeres en las actuaciones, otro término que se utilizó hasta mediados del siglo XIV para designar a las juglaresas andantes fue soldadera, palabra derivada de salario, es decir, de la soldada que percibían por su trabajo. En general, las soldaderas eran consideradas de bajo nivel artístico y social y, además, tenían mala reputación. En su ya clásico estudio Poesía juglaresca y orígenes de las literaturas románicas, Ramón Menéndez Pidal, si bien admitía que el vocablo podía tener un sentido más general, definía a la soldadera como "mujer que vendía

23 Cfr. R. Ménendez Pidal, Poesía juglaresca y origenes de las literaturas románicas, Madrid, I957, pp. 33-34.

${ }_{24}$ F. Rico, Los discursos del gusto: notas sobre clásicos y contemporáneos, Barcelona, 2003, p. 257. 
al público su canto, su baile y su cuerpo mismo", ${ }^{25}$ es decir, como una prostituta. En realidad, la cuestión era un poco más complicada. La juglaresa, por su condición de artista profesional que trabajaba a cambio de una soldada, era exactamente eso, una soldadera; ahora bien, la moral misógina de la época provocó una confusión entre la profesión de quienes vendían su arte y la profesión de quienes vendían su cuerpo, lo cual, en parte, se debía a la mala reputación que también poseían los juglares hombres.

Con frecuencia, pues, a las soldaderas se las consideraba prostitutas, aunque no lo fuesen realmente todas. Así es en nuestro Libro de Apolonio, donde se califica al comprador de Tarsiana, quien, como sabemos, es propietario de un burdel, como "señor de soldaderas", lo cual sin duda significa que aquí soldadera se utiliza como sinónimo de prostituta. ${ }^{26}$ Además, tenemos constancia del caso de la soldadera gallega María Pérez, conocida como la Balteira, personaje que existió realmente en el siglo xiII, quien toda su vida tuvo una dudosa reputación. Originaria de la provincia de La Coruña, exactamente de Betanzos, María pertenecía a una familia noble, poseía bienes propios y frecuentó las cortes de los reyes de Castilla y León Fernando iII y Alfonso x. A ella están dedicadas como mínimo catorce cantigas de escarnio ${ }^{27}$ y entre los cantores críticos de esta soldadera hallamos al propio rey Sabio. Dichas cantigas retratan a la Balteira como una gran pecadora, blasfema, impía y sexualmente promiscua, es decir, ofrecen un perfecto retrato

25 R. Ménendez Pidal, Poesía juglaresca, p. 32; insiste sobre este aspecto M. C. Pallares Méndez, A vida das mulleres na Galicia medieval (IIO0-I50o), Santiago de Compostela, I993, que dice que las soldaderas eran "mulleres que acompańaban os soldados nos seus desprazamentos ou que vivían na corte en compañía de xograis e trobadores, como testemuño dunha prostitución non estabilizada, non organizada" (p. 85). Sobre la cuestión, véase también D. K. Filıos, Performing Women in the Middle Ages: Sex, Gender, and the Iberian Lyric, New York, 2005, pp. 33-81.

$26 \mathrm{~L}$. Allegri, Teatro e spettacolo nel Medioevo, Roma-Bari, 2003, subraya que asociar el oficio de la juglaresa con el de la prostituta es fruto de una serie de factores, "dal tradizionale pregiudizio anche del mondo classico verso le donne attrici alla condizione già degradata e ambigua che le giullaresse hanno ricevuto in eredità dalle mime tardo-romane, all'ostilità ancor più virulenta della cultura cristiana, che in un attore donna non può che vedere il risultato di due principi negativi che si moltiplicano a vicenda. Ma è certo che la presenza costante di donne, a torto o a ragione accusate di esercitare anche la prostituzione, costituisce un ulteriore strumento di degradazione sociale della professione attorica. E comunque, anche quando la figura della giullaressa subisce un processo analogo a quello del giullare, con l'accettazione sociale e professionale in seno alle corti, il suo ruolo, salvo rari casi, è comunque sempre subalterno, esecutivo, con le funzioni primarie di danzatrice e cantante" (p. 90).

27 Las cantigas de escarnio dedicadas a la Balteira constituyen un verdadero ciclo, como señaló M. Rodrigues LAPA en su Liçôes de literatura portuguesa. Época medieval, Lisboa, 1934. Cfr. también el análisis del conjunto de poemas en C. Alvar, "María Pérez, Balteira", Archivo de Filología Aragonesa, 36-37, 1985, pp. II-40. 
descortés del personaje. ${ }^{28}$ Conviene señalar que María no fue la única soldadera objeto de escarnio en la lírica gallego-portuguesa y que, en general, los ataques no eran de tipo moralista, sino de un sarcasmo rayano en la vulgaridad.

Otro caso interesante e históricamente documentado de la mala fama de la mujer artista en el siglo Xv es el de Isabel de Sant Jordi, hermana del poeta Jordi de Sant Jordi. Conocemos su historia gracias a unas cartas, algunas firmadas por el rey Alfonso el Magnánimo y otras por su mujer, doña María de Castilla, referidas a la dificultosa admisión de Isabel como monja en el entonces prestigioso monasterio cisterciense de la Zaidía, situado cerca de Valencia. Pese a las insistentes gestiones que realizaron el rey y su esposa desde la primera década del siglo XV, Isabel no fue aceptada en la Zaidía antes de I426. Si las monjas se empeñaban en rechazar a Isabel, debía de existir un impedimento gravísimo, un obstáculo que ni la intervención directa de los reyes podía salvar. En efecto, gracias al hallazgo de una carta fechada el 27 de abril de I4I6, sabemos que el problema radicaba no tanto en el hecho de que los Sant Jordi fueran de origen musulmán, sino en que muy probablemente Isabel había ejercido alguna actividad juglaresca. En la carta se lee:

Per part de la reverent abbadessa del monastir de la Çaydia d'aquesta ciutat, nos és estat explicat com lo molt alt senyor rey ha manat a aquella que reeba e do l'hàbit del dit monastir a una dona, germana d'en Jordiet, lo qual se diu que és de la sua cambra, dient en la dita explicació que açò hauria proveït lo dit senyor, ignorant e no informat com les dones qui són admeses en monges del dit monestir són donzelles de gran estat, ço és, filles de nobles hòmens, cavallers e de notables ciutadans. E, segons nosaltres sabíem, lo dit Jordiet e germana de aquell eren fills de hun moro catiu qui aprés fon christià e libert, hoc e axí mateix la dita dona que és diffamada de son cors, concloent, en effecte la dita abbadessa que aquella, e totes les monges conventuals del dit monestir, venien acordades de desemparar aquell ans de soferir que tal persona fos admesa en llur convent. ${ }^{29}$

Si bien es cierto que en el documento no aparece referencia alguna al apellido de Jordiet y de Isabel, no hay duda de que el caso mencionado coincide exactamente con la situación del poeta y su hermana. En 1953, el erudito Jordi Rubió i Balaguer ya había levantado ciertas sospechas acerca de los orígenes de la familia Sant Jordi: "Seria sorprenent que pertanyés al seu llinatge [de Sant Jordi] el Joan de Sant Jordi que, anys més tard, apareix a la cancelleria reial i fou secretari de

28 Resumo aquí las noticias sobre el personaje que se encuentran en T. López, "María Balteira, señora do tempo pasado", Cinguidos per unha arela común: Homenaxe ó professor Xesús Alonso Montero, eds. R. Álvarez y D. Vilavedra, 2 vols., Santiago de Compostela, 1999, vol. II, Literatura, pp. 795-8I2.

29A. Rubio, Epistolari de la València medieval, 2 vols., Valencia-Barcelona, 1998, vol. II, pp. 333-334. 
Joan II. Era convers i el I49I fou cremat en estàtua." ${ }^{30}$ Dicha hipótesis explicaría perfectamente la actitud hostil de las religiosas hacia Isabel. Por su parte, Martín de Riquer y Lola Badia rechazaban la hipótesis de Rubió i Balaguer; según ambos, el motivo que impedía a Isabel de Sant Jordi el acceso a la Zaidía nada tenía que ver con problemas de limpieza de sangre, sino que se trataba simplemente de una cuestión económica. Para entrar en el monasterio de la Zaidía se necesitaba una dote considerable y tal vez la familia Sant Jordi no estaba en condiciones de facilitársela a Isabel. Sin embargo, los mismos Riquer y Badia documentan que el rey llevó a cabo personalmente todos los trámites necesarios para que Jordi de Sant Jordi tuviese la cantidad de dinero suficiente para resolver la cuestión. ${ }^{3 \mathrm{I}}$ Por lo tanto, es de suponer que el problema económico debía de ser totalmente secundario, ya que las concesiones reales representaban unas garantías suficientes para cualquier madre superiora, incluso para la de un monasterio elitista como el de la Zaidía. El contenido de la carta del 27 de abril de 1416 parece confirmar la intuición de Rubió i Balaguer, es decir, que se podía tratar de un problema racial: el documento deja claro que había una mancha en el orígen de Jordi e Isabel de Sant Jordi, que no eran judíos conversos como había supuesto el estudioso, sino musulmanes conversos, "eren fills de hun moro catiu qui aprés fon christià e libert".

Por otra parte, y ahora llegamos al tema que nos interesa para nuestro discurso, en esta misma carta también se dice que Isabel "és diffamada de son cors". Esto podría significar que en el pasado se había dedicado a alguna actividad relacionada con la exhibición del cuerpo, como por ejemplo el baile. Sabemos que, desde el comienzo de su reinado, Alfonso el Magnánimo acogió en su corte un número considerable de juglares, bailarines y músicos, muchos de ellos de origen musulmán; esa misma corte, instalada en Nápoles, se convertiría con los años en uno de los mayores centros musicales del siglo xv. Además, el rey se mostró desde muy joven extraordinariamente abierto respecto a judíos y musulmanes, actitud que mantuvo a lo largo de toda su vida..$^{32}$ A propósito de los Sant Jordi, podemos

30 J. Rubió i Balaguer, Literatura catalana, en G. Díaz Plaja (dir.), Historia general de las literaturas hispánicas, 5 vols., Barcelona, I949-1958, vol. III (1953), pp. 729-930 (cito por la edición catalana, J. Rubió i Balaguer, Història de la literatura catalana, 3 vols., Barcelona, I984, vol. I, pp. 325.

3I M. De Riquer y L. Badia, Les poesies de Jordi de Sant Jordi, Valencia, 1984, pp. I5-I6 y 44-53.

32 En noviembre de I4I4, por ejemplo, el entonces príncipe Alfonso se encontraba en Zaragoza cuando el gran fraile predicador san Vicent Ferrer decidió multar a los judíos y musulmanes que hubiesen llegado tarde a uno de sus sermones. Alfonso aceptó y respetó la decisión del fraile, pero se las ingenió para que nadie tuviera que pagar. Años más tarde, el Magnánimo subvencionó los estudios universitarios del poeta Pedro de Santa Fe, un judío converso que formó parte de su séquito personal. En I424, Alfonso rescató a una de las bailarinas de corte, la conversa Caterina, que había escandalizado a los inquisidores valencianos por llevar un traje moresco. Cfr. A. RaYder, Alfonso the Magnanimous. King of Aragon, Naples and Sicily, I396-I458, Oxford, I990. 
lanzar la hipótesis de que podía tratarse de una familia de artistas, mejor dicho, de juglares musulmanes estrechamente relacionados con la corte de Alfonso, tan estrechamente que el poeta llegó a ser camarero personal del rey.

Huelga decir que nos movemos en el resbaladizo campo de las suposiciones; sin embargo, recordemos que una autoridad literaria como don Íñigo López de Mendoza, marqués de Santillana, en su Prohemio e carta (ca.I449), decía que nuestro poeta "conpuso asaz fermosas cosas, las quales él mesmo asonava, ca fue músico exçellente", ${ }^{33}$ subrayando así sus buenos conocimientos musicales. No dudamos de que la afirmación del marqués sea verídica, pues don Íníigo debió de conocer personalmente a Jordi de Sant Jordi, ya que ambos coincidieron en la corte del Magnánimo (en su juventud, el futuro marqués fue copero del rey). ${ }^{34} \mathrm{Y}$ si Jordi de Sant Jordi fue trovador, ${ }^{35}$ es muy posible que su hermana fuese bailarina. Como puede verse, en el siglo del marqués de Santillana y de Jordi e Isabel de Sant Jordi, la creatividad de la mujer y las voces femeninas tenían un protagonismo tan escaso como el de siglos anteriores, y como el que tendrían en siglos venideros. Además, persistía la errónea equivalencia entre mujer artista y mujer de dudosa reputación.

Volviendo a Tarsiana, sus palabras demuestran, a mi parecer, que, a pesar de los equívocos y la mala reputación, existió una categoría de mujeres profesionales del arte juglaresco que se ganaba la vida sin tener necesariamente una conducta impropia. Gracias a sus actuaciones públicas, nuestra heroína empieza a ganar un sueldo honestamente; y no olvidemos que ella ejerce el oficio con su maestría, es decir, gracias a una sabiduría adquirida a través de sus estudios, lo cual la distingue de otra clase de juglaresas, que evidentemente no eran letradas. Además, las palabras de Tarsiana parecen sugerir que la mujer artista reivindicaba su formación cultural para ser merecedora de respecto. No obstante, la situación real debió de ser algo diferente. A lo largo de la Edad Media, las mujeres cultas recibieron no pocas críticas de los hombres letrados de su época, quienes tenían sus prevenciones frente a las damas de la nobleza y de la alta burguesía que se inte-

33 Marqués de Santillana, Obras completas, eds. Á. Gómez Moreno y M. P. A. M. Kerkhof, Barcelona, 1988, p. 448.

34 Es muy probable que el poeta aprendiera los conocimientos musicales de su padre, el "esclau libert” que, según sabemos, se llamaba Joan. Pues bien, si Jordi fue un excelente músico, ¿por qué no suponer que su hermana Isabel, antes de tomar la decisión de entrar en un convento, había sido bailarina y, como tal, "diffamada de son cors"? En mi opinión, es muy posible que el origen musulmán de los Sant Jordi y el oficio que probablemente ejerció Isabel provocasen la exacerbada oposición de las monjas de la Zaidía. En cualquier caso, es importante señalar que, más de diez años después, cuando por fin logró entrar en el monasterio, Isabel no tuvo ningún problema de integración y hasta llegó a ser borsera y sagristana.

35 Para la definición de Jordi de Sant Jordi como 'último trovador', cfr. Jordi DE SANT Jordi, L'amoroso cerchio. Poesie dell'ultimo trovatore, ed. D. Siviero, Milano-Trento, I997, p. I9. 
resaban por la literatura; y no hace falta recordar que dicha actitud se prolongó durante muchos siglos. La mujer era vista fundamentalmente como objeto, no como sujeto; como inspiradora de obras literarias, a veces era una figura negativa, blanco de los ataques misóginos más crueles, ${ }^{36} \mathrm{y}$ a veces era un modelo idealizado de perfección y hermosura.

En este sentido, hasta la interpretación de la fin'amor de los trovadores ofrece no pocas ambigüedades y ha sido y es objeto de múltiples lecturas. Por obvias razones de espacio, no puedo analizar aquí las diferentes y plurales teorías; ${ }^{37}$ sólo quiero recordar que por una parte se ha teorizado que la fin'amor presuponía una elevación del estatus de la mujer, nombrada soberana absoluta por los poetas, quienes dejan a un lado su voluntad para satisfacer los deseos de la dama. Así, el yo lírico alude con frecuencia al camino de autosuperación que van trazando las pruebas que le impone la mujer, la cual se erige en juez supremo al evaluar las cualidades y capacidades de su pretendiente para superar dichas pruebas. Por lo tanto, desde esta perspectiva, la mujer constituye un ser superior y todopoderoso para los trovadores. Pero, por otra parte, también hay críticos que defienden que la fin'amor no es más que la expresión del deseo masculino, deseo carnal de los jóvenes, que esperan con impaciencia poder satisfacerlo, o deseo de los caballeros que viven en las cortes, para quienes la mujer del seńor reemplaza la figura de la madre y al mismo tiempo evoca el deseo sexual. Para estos caballeros, pues, la mujer del señor es una presa difícil de conquistar, pero la recompensa que les espera es mucho más excitante que cualquier ‘botín’ fácil de obtener. Así, si por un lado "la mujer sufre un proceso de revalorización, que la convierte en soberana del amante-poeta-vasallo que mientras espera el premio final se contenta con contemplarla", por otro surge una especie de "erotismo de la mirada, un voyerismo individualista" del yo lírico masculino, que hace de su amor un sentimiento estático y narcisista, puesto que "la mujer aparece más como medio que como fin; el amante, en una actitud egoísta y pueril parece preocuparse de su propio gozo y no del deleite de la amada”. ${ }^{8}$

36 Es de sobra sabido que la misoginia de la cultura medieval es consecuencia del pensamiento oficial de la cultura cristiana: "La mujer como un ser no sólo inferior al hombre, sino como origen y fuente de todo mal para el hombre configura una idea que, a partir de San Pablo, fue repetida y argumentada hasta la saciedad por los textos dotrinales y teológicos cristianos. De ahí pasó a la literatura, en latín y en lengua vulgar: si podemos hablar de 'misoginia' la cultura medieval no es porque nuestros autores fueran genéticamente misóginos [...] sino porque [...] crecieron y se educaron en el seno de una cultura religiosa como la cristiana cuyo pensamiento oficial [...] fue profundamente misógino" (R. M. MÉrida Jiménez, Damas, santas y pecadoras. Hijas medievales de Eva, Barcelona, 2008, p. 108).

37 Sobre la compleja cuestión, se puede ver S. Gaunt, Gender and Genre in Medieval French Literature, Cambridge, I995, en particular pp. I22-I79. Cfr. también C. Di Girolamo, I trovatori, pp. 32-58. 38 R. García Pradas, "De la cortesía y la finiamors a la eclosión del lirismo erótico en el Medioevo 
Sea como fuera, creo que no se puede negar que en el universo poético creado por los trovadores a veces la mujer es más un objeto pasivo que un sujeto activo. Sin embargo, en el mundo real de los trovadores existieron mujeres que sí desempeñaron un papel activo: me refiero, por una parte, a las señoras cultas y con dinero que patrocinaban la actividad de los trovadores, los protegían y alojaban en sus residencias y remuneraban su trabajo; por otra, a un grupo de mujeres fundamentales para nuestro discurso, las trobairitz, autoras de poesía en primera persona, activas entre mediados del siglo xII y mediados del xiII, los años más esplendorosos de la producción trobadoresca. ${ }^{39}$ Se conocen los nombres de unas dieciséis trobairitz, aunque conservamos más de una composición sólo de dos de ellas..$^{40}$ Indudablemente, hubo más, pero, como dijo Peter Dronke, "For each language and culture, we are much at the mercy of the selector - the predominantly male word of chroniclers and copyists". ${ }^{41}$ No es de extrañar que la transmisión de obras de autoras haya sido tan desafortunada y fragmentaria, y no solamente porque en la época medieval, si bien hubo una minoría de trovadores que respetaron a las mujeres sabias en general y a las trobairitz en particular, por lo general la actitud dominante frente a ellas fue profundamente misógina. ${ }^{42}$ Gaunt sintetiza muy bien el problema al recordar que "Feminist scholarship on the formation of literary canons chats the strategies men use to suppress women's writing [...] the

occitano", en De la canción de amor medieval a las soleares. Profesor Manuel Alvar in memoriam, ed. P. M. Piñero Ramírez, Sevilla, 2004, pp. I23-133, p. I24.

39 I. DE RiQuer, "Las trobairitz", en Breve historia feminista de la literatura española (en lengua gallega, catalana y vasca), 6 vol., coord. I. M. ZAVALA, Barcelona, 1993-2000, vI, pp. 27-39.

40 Hay que considerar que "entre los 2500 textos poéticos de trovadores provenzales, existen unas 46 canciones que corresponden a una voz femenina que no se han atribuido a ningún trovador" (ivi, p. 29) y que es probable que sean de una autora. Por su parte S. Gaunt, Gender and Genre, hace notar que si el corpus de las trobairitz es tan escaso es porque "women were silencied by the canso or rendered virtually inaudible in the androcentric space of the chansonniers. But the surviving cansos of the trobairitz are testimony to the fact that if more women's voices from the Middle Ages have not survived, this does not mean women did not articulate their desires" (p. 179).

4I P. Dronke, Women writers of the Middle Ages. A Critical Study of Texts from Perpetua to Marguerite Porete, Cambridge, 1984, p. 98. Dronke observa también que "Yet songs by joglaresas are not recorded under their names - just as, in the eleventh century, not even one of the women's lyrics enshrined or adapted in the Mozarabic kharjas was attribuited as a composition to a woman [...] The jograsesas whon we know by name were remembered for jests about their adventurous or scandalous lives, not for they lyrics. [...]” (ibidem).

42 Un claro ejemplo de esta actitud negativa, como recuerda I. de Riquer, son los versos de uno de los Proverbios de Cerverí de Girona: "Melor estar faria ab due grans serpens / que ab femna que sia mala e trop sabens". ISABEL DE RIQUeR añade que "El gran trovador catalán no hacía más que unirse a otros escritores de su época en esta prevención hacia las damas de la nobleza y de la alta burguesía que se interesaban por la literatura" ("Las trobairitz", p. 39). Véase también F. López eSTRADA, "Las mujeres escritoras en la Edad Media castellana", en La condición de la mujer en la Edad Media, Madrid, 1986, pp. 9-38. 
small number of chansonniers which transmit trobairitz songs may suggest they were deliberately excluded from some collection". ${ }^{43}$

Los trovadores, como es sabido, componían por escrito sus textos y les ponían música y los juglares difundían esta producción poética cantándola. Normalmente, cada juglar tenía su repertorio y muchos juglares trabajaban siempre con el mismo trovador; también existieron trovadores-juglares y trovadores que provenían de la juglaría. Esto quiere decir que a veces el mismo trovador podía actuar como juglar de sí mismo. Así pues, cuando la trobairitz Castelloza, de principios del siglo XIII, afirma en su canción Amic, sie•us trobes avinen que "fauc chanssos per tal q'eu fass' auzir / vostre bon pretz; don eu no.m puosc sofrir" (hago canciones para que se conozca vuestro gran mérito), pero que "e no·us o man q'ieu mezeussa-us o dic", es decir, "no os lo envío [mi canto] por mensajero sino que os lo digo yo misma" (vv. 5-6 y 44), ${ }^{44}$ probablemente se está refiriendo al hecho de que ella misma cantaba sus composiciones, actuando, pues, como juglaresa, aunque imaginamos que dentro del reducido espacio de una corte y no en las plazas. Esta, mutatis mutandis, vendría a ser la situación de Tarsiana, que así se propone como una especie de trobairitz-juglaresa del área ibérica. Y si ésta reivindica tan decididamente su papel de juglaresa no "de buen mercado", sino de otra categoría, es porque muy probablemente — como he intentado argumentar- debieron de existir juglaresas cultas y honestas, que hasta actuaban por su cuenta con total autonomía y no como acompañantes de un juglar, y capaces de producir piezas para su repertorio, tal como hace Tarsiana y como es probable que hiciese Castelloza.

En definitiva, el Libro de Apolonio es un valioso testimonio de que, en una Edad Media androcéntrica y reconstruida tradicionalmente desde una perspectiva masculina, hubo mujeres que ejercieron los mismos oficios que los hombres. Tal es el caso de la juglaría, oficio que no desembocaba necesariamente en la prostitución. El hecho de que Tarsiana logre escapar de su destino de soldadera de burdel ejerciendo como juglaresa confirmaría por lo tanto la existencia de una categoría de auténticas profesionales en el arte de la juglaría.

43 S. Gaunt, Gender and Genre, p. 158.

44 Utilizo la edición de A. Rieger, Trobairitz. Der Beitrag der Frau in der altokzitanischen höfischen Lyrik, Tübingen, 1991, pp. 519-520. 